\title{
EFEITO DE VOLUMES DE ÁGUA DE IRRIGAÇÃO NO REGIME HÍDRICO DE SOLO COESO DOS TABULEIROS E NA PRODUÇÃO DE COQUEIRO ${ }^{(1)}$
}

\author{
Fernando Luis Dultra Cintra ${ }^{(2)}$, Ronaldo Souza Resende ${ }^{(2)}$, Maria de Lourdes \\ da Silva Leal ${ }^{(2)}$ \& Jeane Cruz Portela ${ }^{(3)}$
}

\begin{abstract}
RESUMO
A formação dos solos dos tabuleiros está relacionada a sedimentos arenoargilosos e argilosos do grupo Barreiras do Terciário, que são, em geral, arenosos, pobres em nutrientes e em matéria orgânica, tipicamente cauliníticos e caracterizados por camadas adensadas (camadas coesas) localizadas, quase sempre, entre 20 e $60 \mathrm{~cm}$ de profundidade. Por apresentarem elevados níveis de adensamento e se situarem próximas à superfície do solo, as camadas coesas promovem alterações expressivas no movimento de água no solo, com repercussão negativa no desenvolvimento e na produtividade das plantas. Esse trabalho teve como objetivo comparar volumes de água de irrigação quanto ao movimento e distribuição de água em Argissolo Amarelo coeso dos Tabuleiros Costeiros e seu reflexo em variáveis de produção de coqueiro-anão-verde. Foram testados três volumes de água de irrigação: 50, 100 e $150 \mathrm{~L} \mathrm{~d}^{-1}$ em esquema experimental inteiramente casualizado, com seis repetições, sendo a planta considerada uma parcela. Na comparação do número de cachos e de frutos por planta e volume de água de coco por fruto, utilizou-se o mesmo esquema experimental inteiramente casualizado, porém com quatro repetições e nove plantas úteis por parcela. $O$ monitoramento da umidade do solo foi feito com sondas TDR a partir de leituras semanais de sensores localizados a $0,15,0,30,0,60,0,90$ e $1,2 \mathrm{~m}$ de profundidade. Com base nos resultados obtidos, concluiu-se que 100 e $150 \mathrm{~L} \mathrm{~d}^{-1}$ de água promoveram redução na expressão do adensamento na camada coesa, fato não observado no tratamento $50 \mathrm{~L} \mathrm{~d}^{-1}$. A produção média de frutos por planta e o volume de água de coco por fruto foram maiores no tratamento $150 \mathrm{~L} \mathrm{~d}^{-1}$. Os tratamentos testados, no entanto, mostraram-se insuficientes para promover a inflexão da curva
\end{abstract}

\footnotetext{
(1) Recebido para publicação em outubro de 2008 e aprovado em maio de 2009.

(2) Pesquisadores da Embrapa Tabuleiros Costeiros. Av. Beira Mar 3250, CEP 4001-970 Aracaju (SE). E-mails: fcintra@cpatc.embrapa.br; ronaldo@cpatc.embrapa.br; lurdinha@cpatc.embrapa.br

(3) Engenheira-Agrônoma, Doutoranda em Solos e Nutrição de Plantas, Universidade Federal do Rio Grande do Sul - UFRGS. Av. Bento Gonçalves 7712, CEP 91540-000 Porto Alegre (RS). E-mail: 00145086@ufrgs.br
} 
de resposta das variáveis de produção, que apresentaram valores crescentes em função dos volumes de água de irrigação testados.

Termos para indexação: tabuleiros costeiros, coqueiro-anão-verde, TDR

\author{
SUMMARY: EFFECT OF IRRIGATION SUPPLY ON THE WATER REGIME \\ OF A HARDSETTING TABLELAND SOIL AND ON COCONUT \\ YIELD
}

\begin{abstract}
The origin of tableland soils is related to sandloam and loam sediments of the Tertiary Barreira group. Generally they are sandy with poor contents of nutrients and organic matter. They are also typically kaolinitic and characterized by hard cohesive layers (hardsetting soils) normally located at a depth between 20 and $60 \mathrm{~cm}$. Since the soil density of the hardsetting layers is high and because they are near the surface, they remarkably modify the soil water movement and affect plant development and yields. This study aimed to assess the effect of different irrigation water levels on the water movement and distribution in a Kandic Ustult hardsetting soil of coastal tablelands of Brazil and their influence on the yield of green dwarf coconut. Three levels of irrigation water were investigated: 50,100 and $150 \mathrm{~L} \mathrm{~d}^{-1}$ in a completely randomized design with six replications and one tree per plot. The bunch and fruit number per tree versus the coconut water volume were also studied based on the same experimental design, but with four replications and nine trees per plot. The soil moisture was monitored by TDR probes, based on weekly readings of sensors at depths of 0.15, 0.30, 0.60, 0.90, and $1.20 \mathrm{~m}$. It was concluded that application of 100 and $150 \mathrm{~L} \mathrm{~d}^{-1}$ water resulted in a reduction of the density of the hard layer, unlike when a supply of $50 \mathrm{~L} \mathrm{~d}^{-1}$. The mean fruit yield per tree and the coconut water volume per fruit were the highest at $150 \mathrm{~L} \mathrm{~d} \mathrm{~d}^{-1}$ irrigation. However, none of the treatments caused an inflection on the response curve of the yield variables, which increased with the tested water supply levels.
\end{abstract}

Index terms: coastal tableland, green dwarf coconut, TDR probe.

\section{INTRODUÇÃO}

A fruticultura irrigada em geral e, em especial, a cultura do coqueiro-anão-verde para a produção de água de coco têm grande importância no agronegócio dos Tabuleiros Costeiros por sua participação na geração de emprego e de renda no meio rural, representando uma das principais vocações agrícolas dessa unidade de paisagem. Souza \& Souza (2008) ressaltam a importância da produção agrícola dos tabuleiros Costeiros do Nordeste, que, segundo os autores, detêm $88 \%$ do coco, $68 \%$ do caju, $73 \%$ do mamão, $65 \%$ do abacaxi, $90 \%$ do dendê, $48 \%$ do cacau, $33 \%$ da mandioca e $65 \%$ da cana-de-açúcar. No entanto, o sucesso econômico dessas culturas está diretamente relacionado com a forma de utilização dos recursos naturais água e solo. A água é um recurso cada dia mais escasso em todo o mundo, motivo pelo qual é urgente a adoção de estratégias para racionalização do seu uso. Quanto ao solo, o manejo inadequado tem contribuído para acelerar processos de degradação com danos de ordem econômica, social e ambiental para produtores e sociedade como um todo.

As principais classes de solo dos tabuleiros costeiros são os Latossolos Amarelos e Argissolos Amarelos, ambos, em geral, ácidos a fortemente ácidos, com $\mathrm{pH}$ em água entre 4,0 e 5,0; são quase sempre álicos e apresentam CTC muito baixa. Quanto à mineralogia, a fração areia caracteriza-se pelo predomínio quase absoluto do quartzo, com valores entre 95 e $100 \%$, e, na fração argila, há predomínio da caulinita, com percentagem entre 70 e $90 \%$. Os Argissolos Amarelos diferem dos Latossolos Amarelos pelo gradiente textural mais alto, muitas vezes com mudança textural abrupta (Jacomine, 2001)

Os principais problemas relacionados ao movimento e armazenamento de água nesses solos dos Tabuleiros estão condicionados a horizontes coesos subsuperficiais, comuns nesta unidade de paisagem. Ribeiro (2001) ressalta que os "horizontes coesos dificultam a infiltração e circulação de soluções, gerando um lençol d'água suspenso, sazonal, onde as águas excedentes ascendem e escoam superficialmente do solo carreando argilas dispersas, o que auxilia como um dos processos de empobrecimento em argilas nos horizontes superficiais". Giarola et al. (2007) destacam que o elevado grau de adensamento dos horizontes coesos e das microestruturas limita a penetração das raízes e a circulação de ar e água. Estudos realizados por Cintra \& Libardi (1998) evidenciaram que camadas coesas situadas muito próximas à superfície do solo promoveram grandes alterações na redistribuição da água e contribuíram para a superficialização do sistema radicular de laranjeiras. 
Camadas coesas e baixa capacidade de retenção de água dos solos são fatores que contribuem para aumentar a vulnerabilidade da cultura do coqueiroanão aos déficits hídricos, comuns nos tabuleiros. Por causa da alta taxa de transpiração, o coqueiro-anão consome mais água que as outras variedades e, nas mesmas condições edafoclimáticas, é o primeiro a apresentar os efeitos do estresse hídrico (IRHO, 1992). Esta sensibilidade está relacionada, em grande parte, à superficialização do sistema radicular, impedido de se aprofundar devido à elevada resistência mecânica à penetração das raízes oferecida pelas camadas coesas. Em estudos conduzidos por Cintra et al. (2005), verificou-se que a maior parte das raízes do coqueiroanão-verde cultivado no Platô de Neópolis localizou-se entre 0,2 e $0,6 \mathrm{~m}$ de profundidade, intervalo que concentrou $56 \%$ de todo o sistema radicular.

Por ser uma espécie muito sensível a déficits hídricos, exigente em água e não tolerar má aeração (Nogueira et al., 1998), o coqueiro só atinge bons níveis de produtividade com bom manejo do solo e da água. Segundo Passos et al. (2006), entre os fatores ambientais que limitam o desenvolvimento do coqueiro, a deficiência hídrica é um dos mais importantes. Segundo esses autores, o déficit hídrico na planta é produzido pela falta de água no solo e por perdas excessiva, por transpiração em relação à absorção feita pelas raízes.

Para o bom planejamento da irrigação de um coqueiral, é necessário avaliar a necessidade hídrica das plantas e monitorar os níveis de umidade no solo em diferentes profundidades. Sem esses cuidados, o produtor poderá incorrer em decisões equivocadas na dotação de água contribuindo para desperdício ou baixo rendimento das culturas. Conceição (2004) recomenda o monitoramento permanente da água no solo não só para verificar se o critério adotado para o manejo da irrigação está sendo eficaz, como para acompanhar a umidade do solo na área de exploração do sistema radicular. Libardi (2002), por sua vez, ressalta a importância de estudos detalhados da caracterização hídrica dos solos dos Tabuleiros Costeiros, enfatizando que devem ser realizados por longo período para que se tenha uma idéia correta do regime hídrico do solo.

Este trabalho teve como objetivo avaliar o efeito da aplicação de volumes de água no regime hídrico do solo e nos parâmetros de produção de coqueiro-anãoverde em Argissolo Amarelo coeso dos tabuleiros costeiros, e busca atender a demanda reprimida sobre o tema estratégico para o planejamento da irrigação de coqueiro-anão-verde nos Tabuleiros Costeiros.

\section{MATERIAL E MÉTODOS}

$\mathrm{O}$ experimento foi conduzido na empresa $\mathrm{H}$. Dantas, localizada no Distrito de Irrigação Platô de Neópolis, situado a Nordeste do Estado de Sergipe, na margem direita do Rio São Francisco; latitude $10^{\circ} 17^{\prime} \mathrm{S}$, longitude $36^{\circ} 35^{\prime} \mathrm{W}$. O clima da região, segundo a classificação de Köppen, é do tipo tropical chuvoso com verão seco e precipitação pluvial em torno de $1.200 \mathrm{~mm}$ anuais, apresentando elevada concentração das chuvas e baixa evapotranspiração de referência nos meses de abril a agosto, precipitações pluviais baixas e elevada evapotranpiração de referência nos meses de setembro a março. A altitude da área estudada situa-se em torno de $90 \mathrm{~m}$, a temperatura média anual é de $25^{\circ} \mathrm{C}$, sendo o mês de agosto o mais frio, com temperatura média de $19^{\circ} \mathrm{C} \mathrm{e}$ o mês de março o mais quente com temperatura média de $34^{\circ} \mathrm{C}$, a umidade média anual do ar é de $76,8 \%$, sendo os meses de maio a agosto os que apresentam maior umidade relativa. O relevo é plano com ondulações suaves e o solo foi classificado como Argissolo Amarelo, textura arenosa/média (Embrapa, 2006).

Utilizou-se no experimento a cultura do coqueiroanão-verde, com idade em torno de cinco anos, cultivado no espaçamento $7,5 \times 7,5$ x 7,5 m e com 205 plantas por hectare; o sistema de irrigação foi o de microaspersão no qual foram utilizados dois emissores com vazão média de $30 \mathrm{~L}$ h, por planta, posicionados diametralmente opostos na linha de plantio e distanciados $0,80 \mathrm{~m}$ do estipe.

$\mathrm{O}$ ensaio foi conduzido em delineamento experimental inteiramente casualizado, com três tratamentos de volumes de água por planta 50, $100 \mathrm{e}$ $150 \mathrm{~L} \mathrm{~d}^{-1}$, aplicados nos períodos secos (setembro a março), quatro repetições e nove plantas úteis por parcela. Os dados de produção, número de cachos, número de frutos por planta e volume de água por fruto foram obtidos de 24 colheitas realizadas entre 2002 e 2004. Por haver apenas 18 pontos de medição de umidade disponíveis, foi adotado um novo delineamento experimental para estudo da variável umidade do solo, para o qual foram selecionadas três repetições do experimento original e sorteadas duas plantas, perfazendo seis repetições por tratamento, que passaram a constituir as unidades experimentais para a análise dos dados.

Os dados referentes a número de cachos e de frutos por planta, volume de água por fruto e umidade do solo foram submetidos a análises de variâncias anuais e conjuntas dos anos experimentais, com posterior comparação de médias de tratamentos pelo teste de Tukey, adotando-se um nível de significância de $5 \%$ $(\alpha=0,05)$; os dados de umidade foram também avaliados por períodos seco e chuvoso.

$\mathrm{Na}$ análise de variância conjunta dos dados de produção, adotou-se o modelo estatístico de parcelas subdivididas (no tempo) com os volumes de água nas parcelas e anos nas subparcelas. Para a análise conjunta dos dados de umidade do solo, também foi adotado o modelo de parcelas subdivididas (no espaço) com os volumes de água de irrigação nas parcelas e as camadas de solo nas subparcelas. Neste caso, os 
dados analisados representavam as médias, por período total e períodos seco e chuvoso, de cada repetição dos tratamentos de volumes de água versus profundidade.

O monitoramento da umidade do solo foi efetuado com frequência semanal e por um período de dois anos (2002 e 2003), com base no princípio da reflectometria no domínio do tempo - TDR, utilizando sondas com sensores posicionados nas camadas de solo $0-0,15,0,15$ 0,30, 0,30-0,60, 0,60-0,90 e 0,90-1,20 m (Coelho Filho et al., 2004).

Para a obtenção dos dados das variáveis de produção, respeitou-se o cronograma de colheita da empresa para todas as plantas úteis do experimento (144). Para a medição do volume de água de coco, adotou-se, como procedimento, a retirada do fruto central do cacho seguida de medição do volume de água em proveta graduada de $1.000 \mathrm{~mL}$.

As análises para caracterização física do solo foram feitas com base em metodologias descritas no manual de métodos da Embrapa (Embrapa, 1997) e constaram das determinações de granulometria e densidade de partículas para as quais foram coletadas amostras alteradas. Para a análise de densidade do solo, porosidade total, macroporosidade e microporosidade, e retenção de água no solo, foram utilizadas amostras com estrutura indeformada, coletadas em anéis com dimensões de $0,0599 \mathrm{~m}$ de altura e $0,0537 \mathrm{~m}$ de diâmetro em aparelho tipo Uhland.

A amostragem foi feita nas profundidades 0,00 0,$20 ; 0,20-0,40 ; 0,40-0,60 ; 0,60-0,80 ; 0,80-1,00 ; 1,00$ $1,20 \mathrm{~m}$, em três trincheiras para a elaboração das curvas de retenção de água e em nove trincheiras para as demais análises. Em cada camada de solo, foi coletada uma amostra indeformada para a determinação da densidade do solo, uma para porosidade total, macro e microporosidade, e oito amostras indeformadas para a elaboração da curva de retenção de água no solo, sendo uma amostra para cada uma das tensões aplicadas: 0,$5 ; 1 ; 4 ; 10 ; 33 ; 100$; 500 e $1.500 \mathrm{kPa}$. Foram utilizados funis de placa porosa para a aplicação das tensões 0,$5 ; 1 ; 4 ;$ e $10 \mathrm{kPa}$, câmaras de baixa tensão para os pontos 33 e $100 \mathrm{kPa}$ e de alta tensão para os pontos 500 e $1.500 \mathrm{kPa}$. O ajuste da curva de retenção da água no solo foi feito com base na equação de van Genuchten (1980), utilizando o software SWRC, desenvolvido por Dourado Neto et al. (1990).

A análise econômica para a avaliação da relação benefício/custo do incremento dos tratamentos de irrigação utilizados no experimento teve como base dados de custos e preço médio anual da venda de coco coletados na empresa H. Dantas. Foi considerado o período de 200 dias de irrigação por ano com uma dotação diária de água por planta de $100 \mathrm{~L} \mathrm{~d}^{-1}$ (dotação média utilizada no Platô de Neópolis, obtida em estudos de campo). O custo considerado da água até a entrada da empresa foi de $\mathrm{R} \$ 40,00 / 1.000 \mathrm{~m}^{3}$, e dentro da empresa, composto pela tarifa de consumo e da demanda contratada de energia elétrica, foi de $\mathrm{R} \$ 0,09 / \mathrm{kWh}$ e $\mathrm{R} \$ 12,00 / \mathrm{kWh}$, respectivamente. O preço médio anual do fruto de coco considerado foi de $\mathrm{R} \$ 0,15 /$ unidade.

\section{RESULTADOS E DISCUSSÃO}

Com base nos dados apresentados no quadro 1, podese verificar que o solo estudado tem caráter coeso acentuado, evidenciado pelo aumento da densidade do solo de 1,63 para $1,71 \mathrm{~kg} \mathrm{~m}^{-3}$ e pela redução da macroporosidade de 0,20 para $0,07 \mathrm{~m}^{3} \mathrm{~m}^{-3}$ entre as camadas $0-0,20$ e $0,20-0,40 \mathrm{~m}$, respectivamente. Baixo volume de macroporos e elevada densidade são algumas das principais manifestações dos solos coesos. Quando tais características se apresentam em solo tipicamente arenoso, como o da área estudada, a camada coesa poderá dificultar o suprimento de água para o coqueiro, seja pelo rápido ressecamento da camada superficial do solo, onde se concentram a maioria das raízes e a maior parte das reservas úteis de água, seja por bloquear a ascensão capilar a partir de camadas umedecidas localizadas mais abaixo.

Cintra et al. (2004) observaram camadas adensadas próximas à superfície do solo no Distrito de Irrigação Platô de Neópolis, capazes de promover situações

Quadro 1. Densidade do solo, densidade de partículas, porosidade total, macro e microporosidade e conteúdo das frações minerais do solo para cada camada analisada. Neópolis, SE

\begin{tabular}{|c|c|c|c|c|c|c|c|c|}
\hline \multirow{2}{*}{ Camada } & \multirow{2}{*}{$\begin{array}{l}\text { Densidade } \\
\text { do solo }\end{array}$} & \multirow{2}{*}{$\begin{array}{c}\text { Densidade } \\
\text { de partículas }\end{array}$} & \multicolumn{3}{|c|}{ Porosidade $\left(\mathrm{m}^{3} \mathrm{~m}^{-3}\right)$} & \multirow{2}{*}{ Areia total } & \multirow{2}{*}{ Silte } & \multirow{2}{*}{ Argila } \\
\hline & & & Macro & Micro & Total & & & \\
\hline $\mathrm{m}$ & $\longrightarrow$ & $1^{-3}$ & & & & & $\mathrm{~g} \mathrm{~kg}^{-1}$ & \\
\hline $0,00-0,20$ & 1,63 & 2,6 & 0,2 & 0,18 & 0,38 & 892,11 & 50,23 & 57,66 \\
\hline $0,20-0,40$ & 1,71 & 2,63 & 0,07 & 0,27 & 0,34 & 863,32 & 51,44 & 85,24 \\
\hline $0,40-0,60$ & 1,68 & 2,65 & 0,11 & 0,22 & 0,34 & 831,88 & 65,3 & 102,82 \\
\hline $0,60-0,80$ & 1,66 & 2,63 & 0,16 & 0,17 & 0,33 & 793,31 & 86,29 & 120,4 \\
\hline $0,80-1,00$ & 1,65 & 2,65 & 0,16 & 0,17 & 0,34 & 771,44 & 98,15 & 130,41 \\
\hline $1,00-1,20$ & 1,69 & 2,68 & 0,04 & 0,29 & 0,33 & 755,44 & 111,59 & 132,98 \\
\hline
\end{tabular}


diferenciadas para o desenvolvimento das fruteiras, seja em virtude das alterações no regime hídrico do solo, seja pela elevada resistência mecânica que essas camadas oferecem à penetração das raízes. Bonneau \& Subagio (1999) também identificaram bloqueio da ascensão capilar, assim como redução das reservas úteis de água para o coqueiro em solo com camada subsuperficial endurecida em área sujeita a déficit hídrico.

A macroporosidade foi considerada por Lima et al. (2004) e Santana et al. (2006) como um dos melhores indicadores da coesão dos solos dos tabuleiros, em função da sua menor variabilidade em relação à densidade do solo e condutividade hidráulica saturada. Ao discorrer sobre a importância do uso dos atributos físicos dos solos coesos, Rezende (2002) relatou para densidade do solo $\left(1,73 \mathrm{~kg} \mathrm{dm}^{-3}\right)$, para porosidade total $\left(0,30 \mathrm{~m}^{3} \mathrm{~m}^{-3}\right)$ e para macroporosidade $\left(0,10 \mathrm{~m}^{3} \mathrm{~m}^{-3}\right)$, valores que se assemelham aos apresentados no quadro 1 para a camada 0,20 a $0,40 \mathrm{~m}$ de profundidade. Fortunato (2004) ressaltou nos seus estudos que o horizonte coeso confere grande restrição ao uso agrícola e que, por manifestar-se abaixo do horizonte $\mathrm{A}$, em geral a partir de $0,20 \mathrm{~m}$ de profundidade, não deixa grande volume útil de solo disponível para as plantas.

Com base nessas considerações, é possível supor que a camada coesa identificada neste estudo interfira nas reservas úteis de água, podendo torná-las críticas ao desenvolvimento do coqueiro-anão-verde. Souza et al. (2002) enfatizam a necessidade de utilizar práticas culturais que promovam melhoria na dinâmica e no armazenamento da água no solo antes mesmo de se pensar em interferir nessa unidade de paisagem. A não observância dessa recomendação tem produzido danos consideráveis na produtividade das culturas implantadas nos tabuleiros.

As discussões a seguir são sobre os perfis de umidade obtidos neste estudo e são baseadas na hipótese de que, na presença de água, a expressão do adensamento das camadas coesas é minimizada a ponto de permitir o fluxo vertical ao longo do perfil do solo. Esta hipótese está sustentada nas afirmações de Jacomine (2001) e Ribeiro (2001), os quais ressaltam que os horizontes de subsuperfície dos solos coesos dos Tabuleiros Costeiros se apresentam duros a extremamente duros apenas quando secos, tornandose friáveis quando umedecidos.

Com base nos resumos das análises de variância apresentados no quadro 2 , verifica-se que o efeito dos volumes de água sobre a variável umidade do solo foi significativo somente nos períodos secos, e sobre profundidades foi significativo em todos os períodos considerados. Este resultado contribui para o entendimento de que, mesmo estando totalmente umedecida, situação comum na maior parte da estação chuvosa, a camada coesa exerce algum tipo de restrição ao movimento vertical da água no solo.

Ao se compararem médias dos tratamentos dentro de cada profundidade e na média geral, apenas nos períodos secos (Quadro 3), constata-se que a média da umidade do solo no tratamento $100 \mathrm{~L} \mathrm{~d}^{-1}$, entre 0 $0,15 \mathrm{~m}$ de profundidade, foi igual estatisticamente aos tratamentos 50 e $150 \mathrm{~L} \mathrm{~d}^{-1}$ e que, na camada $0,15-$ $0,30 \mathrm{~m}$, os tratamentos 100 e $150 \mathrm{~L} \mathrm{~d}^{-1}$ foram iguais entre si porém diferiram significativamente de $50 \mathrm{~L} \mathrm{~d}^{-1}$. É possível que a evapotranspiração, mais efetiva na camada mais superficial do solo em resposta ao grande volume de raízes de coqueiro ali localizado, tenha contribuído para ressecar o solo também no volume $100 \mathrm{~L} \mathrm{~d}^{-1}$, igualando-o ao tratamento $50 \mathrm{~L} \mathrm{~d}^{-1}$. Já entre 0,15-0,30 m, onde está a zona mais adensada, as diferenças entre tratamentos devem estar relacionadas à camada coesa e às restrições que causam no movimento da água no solo.

Quando todo o período do estudo foi avaliado (Quadro 4), as diferenças aconteceram apenas entre 0,15 e $0,30 \mathrm{~m}$, demonstrando que o efeito da camada coesa no solo se faz sentir não só nos períodos secos, como também nos chuvosos. Também neste caso, a

Quadro 2. Resumo das análises de variância dos dados de umidade do solo nos períodos chuvoso, seco e global, na média de dois anos experimentais

\begin{tabular}{|c|c|c|c|c|}
\hline \multirow{2}{*}{ Fonte de variação } & \multirow{2}{*}{ GL } & \multicolumn{3}{|c|}{ Quadrado médio } \\
\hline & & Período chuvoso & Período seco & Global \\
\hline Volumes de água (V) & 2 & $12,6691^{\mathrm{ns}}$ & $45,6498 * *$ & $26,4995^{\mathrm{ns}}$ \\
\hline Resíduo (a) & 15 & 10,6459 & 7,1001 & 8,4873 \\
\hline Profundidades (P) & 2 & $19,5490 * *$ & $13,7601 * *$ & $15,8329 * *$ \\
\hline $\mathrm{V} \times \mathrm{P}$ & 8 & $2,0917^{\mathrm{ns}}$ & $2,6972^{\mathrm{ns}}$ & $1,8989^{\mathrm{ns}}$ \\
\hline Resíduo & 60 & 2,8916 & 1,9903 & 2,2660 \\
\hline Coeficiente de variação 1 (\%) & & 26,80 & 25,64 & 25,81 \\
\hline Coeficiente de variação $2(\%)$ & & 13,97 & 13,57 & 13,34 \\
\hline Média geral & & 12,18 & 10,39 & 11,28 \\
\hline
\end{tabular}


Quadro 3. Comparações de médias de umidade do solo (\%) dos tratamentos de volumes de água $\left(\mathrm{L} \mathrm{d}^{-1}\right)$ em cinco profundidades, nos períodos secos

\begin{tabular}{|c|c|c|c|c|c|c|}
\hline \multirow{2}{*}{ Volume de água } & \multicolumn{5}{|c|}{ Profundidade (m) } & \multirow{2}{*}{ Média geral } \\
\hline & $0-0,15$ & $0,15-0,30$ & $0,30-0,60$ & $0,60-0,90$ & $0,90-1,20$ & \\
\hline \multicolumn{7}{|l|}{$\mathrm{L}$} \\
\hline 50 & $9,94 \mathrm{~b}$ & $7,86 \mathrm{~b}$ & 9,79 a & $8,56 \mathrm{a}$ & $8,90 \mathrm{a}$ & $9,04 \mathrm{~b}$ \\
\hline 100 & $12,04 \mathrm{ab}$ & $10,83 \mathrm{a}$ & $11,49 \mathrm{a}$ & $10,10 \mathrm{a}$ & $9,06 \mathrm{a}$ & $10,67 \mathrm{ab}$ \\
\hline 150 & $12,72 \mathrm{a}$ & $11,94 \mathrm{a}$ & $11,66 \mathrm{a}$ & $10,60 \mathrm{a}$ & $10,38 \mathrm{a}$ & $11,46 \mathrm{a}$ \\
\hline Média geral & & & 10,39 & & & 10,39 \\
\hline Erro-padrão & & & 0,7086 & & & 0,4865 \\
\hline DMS & & & 2,42 & & & 1,79 \\
\hline
\end{tabular}

Médias seguidas pela mesma letra não diferem entre si pelo teste de Tukey a 5\%.

Quadro 4. Comparações de médias de umidade do solo (\%) dos tratamentos de volumes de água $\left(\mathrm{L} \mathrm{d}^{-1}\right)$, em cinco profundidades, em todo o período estudado

\begin{tabular}{|c|c|c|c|c|c|c|}
\hline \multirow{2}{*}{ Volume de água } & \multicolumn{5}{|c|}{ Profundidade (m) } & \multirow{2}{*}{ Média geral } \\
\hline & $0-0,15$ & $0,15-0,30$ & $0,30-0,60$ & $0,60-0,90$ & $0,90-1,20$ & \\
\hline \multicolumn{7}{|l|}{$\mathrm{L}$} \\
\hline 50 & $10,99 \mathrm{a}$ & $9,70 \mathrm{~b}$ & $11,31 \mathrm{a}$ & $9,46 \mathrm{a}$ & $9,59 \mathrm{a}$ & $10,24 \mathrm{a}$ \\
\hline 100 & $12,66 \mathrm{a}$ & $12,00 \mathrm{ab}$ & $12,21 \mathrm{a}$ & $10,87 \mathrm{a}$ & $9,75 \mathrm{a}$ & $11,54 \mathrm{a}$ \\
\hline 150 & $13,32 \mathrm{a}$ & $12,48 \mathrm{a}$ & $12,60 \mathrm{a}$ & $11,12 \mathrm{a}$ & $11,21 \mathrm{a}$ & $12,07 \mathrm{a}$ \\
\hline Média geral & & & 11,28 & & & 11,28 \\
\hline Erro-padrão & & & 0,7649 & & & 0,5319 \\
\hline DMS & & & 2,61 & & & 1,95 \\
\hline
\end{tabular}

Médias seguidas pela mesma letra não diferem entre si pelo teste de Tukey a 5\%.

média da umidade no tratamento $150 \mathrm{~L} \mathrm{~d}^{-1}$ divergiu significativamente apenas de $50 \mathrm{~L} \mathrm{~d}^{-1}$, sendo igual estatisticamente à do tratamento $100 \mathrm{~L} \mathrm{~d}^{-1}$.

Na figura 1, pode-se verificar a distribuição de água no solo durante os dois anos de avaliação. Nota-se que as curvas dos tratamentos 150 e $100 \mathrm{~L} \mathrm{~d}^{-1}$ estão próximas entre si e que se distanciam de $50 \mathrm{~L} \mathrm{~d}^{-1}$, à exceção da última camada, cuja percentagem de umidade entre $100 \mathrm{~L} \mathrm{~d}^{-1}$ e $50 \mathrm{~L} \mathrm{~d}^{-1}$ é praticamente a mesma. Pode-se perceber ainda nos volumes $100 \mathrm{~L} \mathrm{~d}^{-1}$ e $50 \mathrm{~L} \mathrm{~d}^{-1}$, perda de umidade na camada $0,15-0,30 \mathrm{~m}$ em relação às camadas adjacentes, e, mais intensamente, em $50 \mathrm{~L} \mathrm{~d}^{-1}$. No volume $150 \mathrm{~L} \mathrm{~d}^{-1} \mathrm{o}$ ressecamento é linear a partir da superfície do solo, proporcionando o umedecimento mais homogêneo do solo em relação aos outros volumes de água testados; o que sugere maior capacidade deste tratamento em romper a expressão dos efeitos do adensamento da camada coesa.

O padrão da curva de umedecimento observado no tratamento $50 \mathrm{~L} \mathrm{~d}^{-1}$, no formato "S" (Figura 1), é frequente nos solos dos tabuleiros costeiros com camadas coesas submetidas a baixos níveis de umidade. Identificam-se, nessa curva, dois pontos de ressecamento, estando o primeiro entre $0,15-0,30 \mathrm{~m}$ e o segundo entre 0,60 e $0,90 \mathrm{~m}$. No primeiro caso, é possível que se deva às alterações estruturais provenientes do maior adensamento da camada coesa

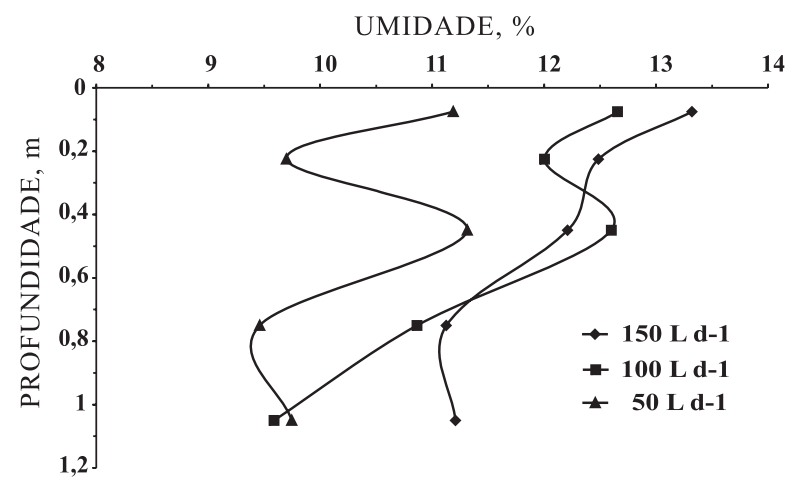

Figura 1. Distribuição da umidade do solo em 2002 e 2003. Média de observações semanais com seis repetições por tratamento. Sensores localizados a $0,075,0,225,0,45,0,75$ e $1,05 \mathrm{~m}$. 
em relação às camadas adjacentes e, no segundo caso, à maior participação da fração argila no complexo soloágua e seu reflexo no potencial mátrico. Segundo Cintra (2006), esse fenômeno promove baixa condução de água nessas camadas, tanto por drenagem interna como por ascensão capilar, e pode causar saturação temporária da camada superficial do solo, se o volume de água aplicado for alto, e ressecamento, se o volume for baixo e coincidir com um sistema radicular extenso, caso do coqueiro-anão-verde.

$\mathrm{Na}$ figura 2 é possível avaliar o comportamento hídrico do solo apenas na estação seca, único período cuja análise de variância detectou diferenças significativas entre os volumes de água. Constata-se nessa figura que todas as curvas apresentam comportamento decrescente da umidade em função da profundidade; que com o volume $100 \mathrm{~L} \mathrm{~d}^{-1}$, a umidade cai acentuadamente para $0,15-0,30 \mathrm{~m}$ e abaixo de 0,45 m; que os níveis de umidade do tratamento $50 \mathrm{~L} \mathrm{~d}^{-1}$ são muito baixos desde a superfície do solo; e que o tratamento $150 \mathrm{~L} \mathrm{~d}^{-1}$ apresenta valores mais elevados de umidade em todas as profundidades, demonstrando maior capacidade para umedecimento do perfil do solo.

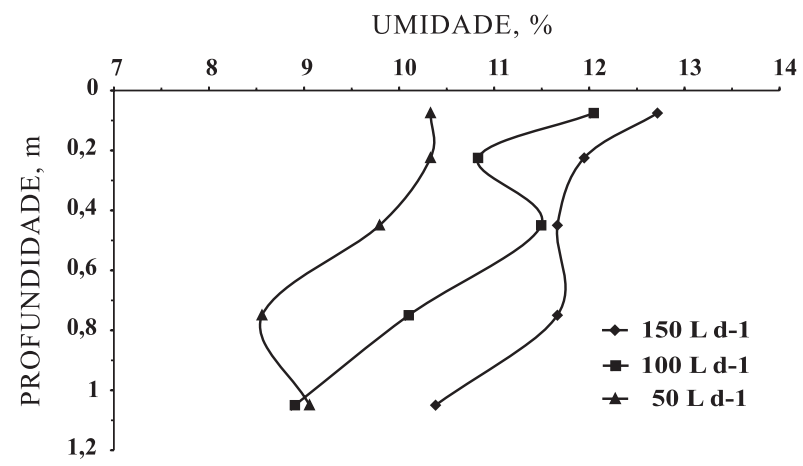

Figura 2. Distribuição da umidade do solo no período seco de 2002 e 2003. Média de observações semanais com seis repetições por tratamento. Sensores localizados a 0,075, 0,225, 0,45, 0,75 e $1,05 \mathrm{~m}$.
Ao se confrontar o comportamento das curvas da figura $2 \mathrm{com}$ os valores de umidade constantes no quadro 5, verifica-se que, na primeira camada, $0-$ $0,15 \mathrm{~m}$, a umidade situou acima da capacidade de campo (10,2\%) em todos os volumes de água testados, e bem abaixo da capacidade de campo (13,33\%) na segunda camada 0,15-0,30 m. Esse distanciamento passa a ser progressivo para as demais camadas de solo, porém com menos intensidade no tratamento $150 \mathrm{~L} \mathrm{~d}^{-1}$.

Na primeira camada da figura 2, 0-0,15 m, na qual a capacidade de campo é próxima de $10,2 \%$, (Quadro 5), a umidade do solo no tratamento $50 \mathrm{~L} \mathrm{~d}^{-1}$ está próxima do limite, e os tratamentos 100 e $150 \mathrm{~L} \mathrm{~d}^{-1}$ encontram-se num patamar superior, ajudados, provavelmente, pelo bloqueio que a camada coesa oferece à infiltração da água. Na segunda camada, 0,15-0,30 m, todos os volumes se distanciam da umidade na capacidade de campo, $13,33 \%$, e o volume de $100 \mathrm{~L} \mathrm{~d}^{-1}$ se aproxima bastante de $50 \mathrm{~L} \mathrm{~d}^{-1}$, demonstrando pouca capacidade daquele tratamento em umedecer a camada mais adensada do solo. Quanto ao tratamento $150 \mathrm{~L} \mathrm{~d}^{-1}$, também se mostra insuficiente para manter a umidade próxima à capacidade de campo o que significa dizer que, mesmo no mais elevado nível de irrigação, as plantas de coqueiro-anão-verde ainda poderão sofrer estresse hídrico.

Considerando que o coqueiro-anão-verde apresenta alta taxa de transpiração (IRHO, 1992), que a evapotranpiração na região estudada é elevada durante a estação seca e que, com estresse hídrico, esta variedade reduz significativamente a condutância estomática (Passos et al., 2006), pode-se esperar grande comprometimento da produção de frutos por planta e volume de água de coco por fruto se os volumes de água de irrigação aplicados nos coqueirais não forem suficientes para atender à grande demanda hídrica desse cultivar.

As análises de variância dos dados de produção, obtidos nos três anos de experimentação (Quadro 6), evidenciaram efeitos significativos dos tratamentos

Quadro 5. Umidade do solo em função das tensões aplicadas nas oito camadas de solo estudadas.Valores médios de três repetições

\begin{tabular}{|c|c|c|c|c|c|c|c|}
\hline \multirow{2}{*}{ Camada } & \multicolumn{7}{|c|}{ Tensões (kPa) } \\
\hline & 0 & 4 & 10 & 33 & 100 & 500 & 1500 \\
\hline $\mathrm{m}$ & \multicolumn{7}{|c|}{ Umidade (\%) } \\
\hline $0,00-0,20$ & 33,40 & 17,97 & 10,20 & 6,72 & 5,96 & 5,73 & 5,71 \\
\hline $0,20-0,40$ & 34,50 & 20,20 & 13,33 & 9,26 & 7,98 & 7,45 & 7,35 \\
\hline $0,40-0,60$ & 33,20 & 22,46 & 12,66 & 8,68 & 8,04 & 7,91 & 7,90 \\
\hline $0,60-0,80$ & 30,70 & 19,79 & 13,50 & 9,22 & 7,68 & 6,95 & 6,80 \\
\hline $0,80-1,00$ & 31,80 & 22,10 & 13,25 & 8,86 & 7,96 & 7,73 & 7,71 \\
\hline $1,00-1,20$ & 31,10 & 21,68 & 13,03 & 9,29 & 8,65 & 8,51 & 8,50 \\
\hline
\end{tabular}


Quadro 6. Resumo das análises de variância dos dados de número de cachos por planta (NCP), número de frutos por planta (NFP) e volume (ml) de água de coco por fruto (VAF) em 2002, 2003 e 2004

\begin{tabular}{lcccc}
\hline & & \multicolumn{3}{c}{ Quadrado médio } \\
\cline { 3 - 4 } Fontes da variação & GL & NCP & NFP & VAF \\
& & $3,0833^{\text {ns }}$ & $1988,7778^{*}$ & $5157,5456^{*}$ \\
Volume de água (V) & 2 & 0,9444 & 290,3056 & 658,9814 \\
Resíduo (a) & 9 & $24,2500^{* *}$ & $6985,5278^{* *}$ & $62197,8384^{* *}$ \\
Anos (A) & 2 & $1,4583^{*}$ & $203,1111^{\text {ns }}$ & $1599,1557^{*}$ \\
V x A & 4 & 0,5000 & 98,6944 & 526,6695 \\
Resíduo & 18 & 7,11 & 15,76 & 5,72 \\
CV 1 (\%) & & 5,17 & 9,19 & 5,11 \\
CV 2 (\%) & & 13,67 & 108,14 & 449,05 \\
Média geral & & & \\
\hline
\end{tabular}

volumes de água de irrigação sobre as variáveis, número de frutos por planta (NFP) e volume de água de coco por fruto (VAF), e não significativo para número de cachos por planta (NCP).

Nas comparações entre médias de tratamentos pelo teste de Tukey, adotando-se um nível de significância de $5 \%$ (Quadro 7), observa-se que o tratamento $150 \mathrm{~L} \mathrm{~d}^{-1}$ resultou em maior número de frutos por planta em relação ao tratamento com $50 \mathrm{~L} \mathrm{~d}^{-1}$, não diferindo, entretanto, daquele com $100 \mathrm{~L} \mathrm{~d}^{-1}$. Esse comportamento pode ter sido resultante, entre outros motivos, do umedecimento mais homogêneo do perfil do solo por esses tratamentos, refletindo no maior e melhor suprimento de água para as plantas, beneficiando assim seu metabolismo. Constatou-se, também, que as plantas que receberam $150 \mathrm{~L} \mathrm{~d}^{-1} \mathrm{de}$ água produziram frutos com maior volume médio de água de coco por fruto do que aquelas que receberam 100 ou $50 \mathrm{~L} \mathrm{~d}^{-1}$. Vale ressaltar que esta variável tem importância fundamental no agronegócio do coqueiroanão-verde por ser a água de coco seu principal produto de comercialização.

Quadro 7. Comparações de médias de número de cachos por planta (NCP), número de frutos por planta (NFP) e volume $(\mathrm{mL})$ de água de coco por fruto (VAF), em função dos tratamentos de volumes de água aplicados $\left(\mathrm{L} \mathrm{d}^{-1}\right)$

\begin{tabular}{cccc}
\hline Volume de água $^{(1)}$ & NCP & NFP & VAF \\
\hline 50 & $13,33 \mathrm{a}$ & $97,42 \mathrm{~b}$ & $434,06 \mathrm{~b}$ \\
100 & $13,42 \mathrm{a}$ & $104,58 \mathrm{ab}$ & $440,37 \mathrm{~b}$ \\
150 & $14,25 \mathrm{a}$ & $122,41 \mathrm{a}$ & $472,71 \mathrm{a}$ \\
Média geral & 13,67 & 108,14 & 449,05 \\
Erro-padrão & 0,2805 & 4,9185 & 7,4105 \\
DMS & 1,11 & 19,44 & 29,28 \\
\hline
\end{tabular}

Tanto a produção média de frutos por planta ano ${ }^{-1}$ como o volume médio de água de coco por fruto apresentaram relação linear com os volumes de água aplicados na irrigação, indicando que doses de água mais altas poderão se refletir em aumento tanto no número de frutos como no volume de água de coco. Esses resultados reforçam o pressuposto de que o suprimento regular em níveis adequados de água para o coqueiro-anão-verde é condição indispensável para o bom desenvolvimento desse cultivar. Olivin \& Ochs (1978) resumem esta importância ao afirmarem que o coqueiro é uma planta muito exigente em água e que sua produção potencial não será atingida se a cultura não dispuser de uma quantidade igual ou muito próxima daquela correspondente à evapotranspiração máxima.

Para estimar a quantidade de água de irrigação para as culturas é preciso levar em conta vários fatores integrados, como clima, tipo de solo e outras variáveis utilizadas no cálculo da estimativa para suprimento de água. Assim é que, para cada região, tem-se um volume de água de irrigação mais adequado para o manejo dos coqueirais. No caso dos tabuleiros costeiros, não se pode deixar de considerar que as camadas coesas exercerão papel preponderante no movimento da água no solo e no suprimento para as plantas.

Barreto et al. (2004) determinaram a variação da demanda hídrica diária para coqueiro-anão-verde na região norte fluminense e obtiveram valores de até $179 \mathrm{~L} \mathrm{~d}^{-1}$ para o mês de fevereiro. No baixo São Francisco, Nogueira et al. (1998) encontraram taxa de $173 \mathrm{~L} \mathrm{~d}^{-1}$ considerando uma cobertura do solo de 80 \%. Em Paraipaba, CE, Miranda \& Gomes (2006) sugerem taxas para coqueiro-anão-verde adulto de até $248 \mathrm{~L} \mathrm{~d}^{-1}$ nos meses de setembro e outubro. Na África, em zonas produtoras de coqueiro expostas a défcits hídricos, Bonneau \& Subagio (1999) identificaram necessidade hídrica da ordem de 250 a $300 \mathrm{~L} \mathrm{~d}^{-1}$.

Neste estudo, foi feita uma estimativa teórica para avaliar a necessidade de água para coqueiro-anão- 
verde com base na curva de retenção de água no solo. A curva apresentada na figura 3 refere-se à camada de solo $0-0,20$ m cuja umidade à capacidade de campo correspondente à tensão de $10 \mathrm{kPa}$ foi de $10,2 \%$ do volume do solo, enquanto que a tensão máxima considerada para efeito de cálculo foi $33 \mathrm{kPa}$ com umidade de $6,7 \%$ do volume do solo.

A partir desses dados, foi possível estimar a necessidade hídrica do coqueiro com base na diferença entre os dois valores de umidade: $10,2 \%$ e $6,7 \%(3,5 \%)$. Portanto, para uma área útil explorada de $12,5 \mathrm{~m}^{2}$ (raio de $2 \mathrm{~m}$ ) e profundidade efetiva das raízes de $0,50 \mathrm{~m}$, o coqueiro disporá de um volume útil de solo de $6,25 \mathrm{~m}^{-3}$ ou $6250 \mathrm{~L}$ e o equivalente a $218 \mathrm{~L} \mathrm{~d}^{-1}(3,5 \%$ de $6250 \mathrm{~L}$ ) de água de irrigação como sua necessidade hídrica estimada. Fazendo os mesmos cálculos para a camada 0,20 a $0,40 \mathrm{~m}$, ter-se-á um volume de água por planta de $254 \mathrm{~L} \mathrm{~d}^{-1}$. Obtém-se, dessa forma, uma necessidade hídrica média de $236 \mathrm{~L} \mathrm{~d}^{-1}$ de água por planta, ou seja, $57 \%$ a mais do que o volume atualmente utilizado de $150 \mathrm{~L}$ de água por dia.

Esta estratégia para a determinação da necessidade hídrica do coqueiro teve como base o princípio de monitoramento da umidade no solo e pode ser divergente das outras metodologias que se baseiam em parâmetros climáticos e na medida direta da água na planta. De qualquer forma, segundo Barreto et al. (2004), o conceito de intervalo hídrico ótimo deverá ser baseado nas práticas de reposição de água no solo numa frequência tal que atenda às necessidades hídricas das plantas em tempo hábil, ou seja, antes que elas sofram efeitos de déficits hídricos. "Essa

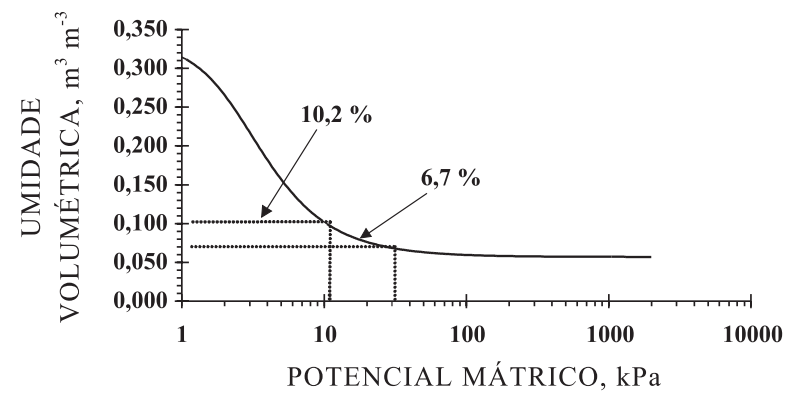

Figura 3. Curva de retenção de água no solo na camada 0,00 a $0,20 \mathrm{~m}$. A capacidade de campo corresponde a $10 \mathrm{kPa}$, e a tensão máxima considerada é de $33 \mathrm{kPa}$. reposição", ressalta o autor, "deve ser administrada na quantidade certa, no momento oportuno e por métodos adequados".

Apesar do acréscimo gradual na produção de frutos e de água de coco por fruto em função dos volumes de água de irrigação, também crescentes, e das diferenças estatisticamente significativas, buscou-se avaliar se os aumentos de produção se refletirão, de alguma forma, em aumento de lucro líquido.

Considerando os incrementos de produtividade obtidos em função dos tratamentos aplicados, o resultado da análise econômica apresentado no quadro 8 demonstra que a receita líquida é positiva (relação benefício/custo maior que a unidade) para todos os intervalos testados. Assim, embora a análise estatística não tenha detectado diferenças significativas entre os tratamentos 100 e 150, para as condições de contorno deste estudo, torna-se economicamente viável a utilização da dose mais alta, que resulta em uma relação benefício/custo de 2,65.

Os preços de nivelamento do fruto para o incremento de custo e receita dos tratamentos 50-100, 50-150 e 100-150 L planta ${ }^{-1}$ dia $^{-1}$ (receita líquida igual a zero) foram de $R \$ 0,10, R \$ 0,07$ e $R \$ 0,06$, respectivamente, considerando a condição de contorno especificada, sendo, portanto, inferior ao preço médio do fruto para a região, que é de $R \$ 0,15$. Deve-se observar que a análise econômica não considerou alguns itens de custo de menor impacto, como o incremento de custo associado ao aumento da produtividade.

\section{CONCLUSÕES}

1. Os volumes de água de irrigação 100 e $150 \mathrm{~L} \mathrm{~d}^{-1}$ foram suficientes para quebrar a expressão dos efeitos do adensamento na camada coesa, fato não observado no tratamento $50 \mathrm{~L} \mathrm{~d}^{-1}$.

2. A aplicação de volumes de água de irrigação inferiores a $100 \mathrm{~L} \mathrm{~d}^{-1}$ poderá comprometer a produção de frutos por planta e, em maior escala, o volume de água de coco por fruto nas áreas de produção de coco do Platô de Neópolis.

3. Os tratamentos testados se mostraram insuficientes para promover a inflexão da curva de

Quadro 8. Análise econômica incremental para os tratamentos de volumes de água 50, 100 e $150 \mathrm{~L}$ planta/dia

\begin{tabular}{cccccc}
\hline Tratamento & $\begin{array}{c}\text { Produtividade } \\
\text { incremental }\end{array}$ & $\begin{array}{c}\text { Custo } \\
\text { incremental }\end{array}$ & $\begin{array}{c}\text { Receita } \\
\text { incremental }\end{array}$ & $\begin{array}{c}\text { Renda líquida } \\
\text { incremental }\end{array}$ & Benefício/custo \\
\hline & frutos/planta & & & & \\
& & & & \\
50-100 L dia ${ }^{-1}$ de planta & 10,1 & 205,67 & 310,57 & 104,90 & 1,51 \\
50-150 L dia ${ }^{-1}$ de planta & 27,8 & 411,34 & 854,85 & 443,51 & 2,08 \\
100-150 L dia ${ }^{-1}$ de planta & 17,7 & 205,67 & 544,27 & 338,60 & 2,65 \\
\hline
\end{tabular}


resposta das variáveis de produção (frutos por ha ano-1 e volume médio de água de coco por fruto), os quais apresentaram valores crescentes em função dos volumes de água de irrigação testados.

\section{AGRADECIMENTOS}

Ao Sr. Marcelo Prado, proprietário da empresa $\mathrm{H}$ Dantas, pela liberação da área experimental e de funcionários para a realização das atividades, e ao $\mathrm{Sr}$ Hildeberto Barbosa dos Santos, responsável técnico da propriedade, pelo apoio permanente durante os trabalhos. A Roberto Alves, assistente de pesquisa, lotado no laboratório de física do solo da Embrapa Tabuleiros Costeiros, pela ajuda nas amostragens de campo e análises em laboratório.

\section{LITERATURA CITADA}

BARRETO, A.N.; SILVA, A.A.G. \& BOLFE, E.L. Irrigação e drenagem na empresa agrícola: Impacto ambiental versus sustentabilidade. Aracaju, Embrapa Tabuleiros Costeiros, 2004. 418p.

BONNEAU, X. \& SUBAGIO, K. Culture du cocotier en zone exposée au risque de sécheresse. Oléagineux, 6:432-439, 1999.

CINTRA, F.L.D. \& LIBARDI, P.L. Caracterização física de uma classe de solo do ecossistema de Tabuleiros Costeiros. Sci. Agric., 55:367-378, 1998.

CINTRA, F.L.D.; PORTELA, J.C.; NOGUEIRA, L.C. \& GORNAT, B. Distribuição de raízes de coqueiro-anãoverde sob sistemas de irrigação localizada em solo dos Tabuleiros Costeiros. Aracaju, Embrapa Tabuleiros Costeiros, 2005. 15p (Boletim de Pesquisa 6)

CINTRA, F.L.D.; PORTELA, J.C. \& NOGUEIRA, L.C. Caracterização físíca e hídrica em solos dos Tabuleiros Costeiros no Distrito de Irrigação Platô de Neópolis. R. Bras. Eng. Agríc. Amb., 8:45-50, 2004.

CINTRA, F.L.D. Coesão de solos dos tabuleiros costeiros: Resultados de pesquisas sobre sistema radicular e atributos físicos e hídricos do solo. In: REUNIÃO BRASILEIRA DE MANEJO E CONSERVAÇÃO DO SOLO E DA ÁGUA, 16., Aracaju, 2006. Anais. Aracaju, Sociedade Brasileira de Ciência do Solo, 2006. CD-ROM.

COELHO FILHO, M.A.; VELLAME, L.M.; COELHO, E.F. \& SOUZA, C.F. Instalação e operação de sistemas de aquisição de armazenamento de dados para monitoramento do sistema solo-planta-atmosfera. Cruz das Almas, Embrapa/Centro Nacional de Mandioca e Fruticultura Tropical, 2004. 135p. (Série Documentos, 143)

CONCEIÇÃO, M.A.F. Irrigação de fruteiras por microaspersão. Jales, Embrapa Uva e Vinho, 2004. 16p. (Circular Técnica, 49)
DOURADO NETO, D.; JONG van LIER, Q.; BOTREL,T. A. \& LIBARDI, P.L. Programa para confecção da curva de retenção de água no solo utilizando o modelo de van Genuchten. Eng. Rural, 1:92-102, 1990.

EMPRESA BRASILEIRA DE PESQUISA AGROPECUÁRIA EMBRAPA. Centro Nacional de Pesquisa de Solos. Manual de métodos de análise de solo. 2.ed. Rio de Janeiro, 1997. 212p.

EMPRESA BRASILEIRA DE PESQUISA AGROPECUÁRIA EMBRAPA. Centro Nacional de Pesquisa de Solos. Sistema brasileiro de classificação de solo. 2.ed. Rio de Janeiro, 2006. 306p.

FORTUNATO, F.F. Sistemas pedológicos nos tabuleiros costeiros do litoral norte do Estado da Bahia: Uma evolução controlada por duricrostas preexistentes, neotectônica e mudanças paleoclimáticas do quartenário. Salvador, Universidade Federal da Bahia, 2004. 366p.(Tese de Doutorado)

GIAROLA, N.F.B.; SILVA, A.P.; LIMA, H.V. \& MARTINS, V.M. Microestrutura de horizontes coesos provenientes de Argissolos Amarelos dos Tabuleiros Costeiros. In: CONGRESSO BRASILEIRO DE CIÊNCIA DO SOLO, 31., Gramado, 2007. Anais. Gramado, Sociedade Brasileira de Ciência do Solo, 2007. CD ROM

IRHO. Alimentation en eau et tolerance à la secheresse. Oléagineux, 47:336-340, 1992.

JACOMINE, P.K.T. Evolução do conhecimento sobre solos coesos no Brasil. In: WORKSHOP COESÃO EM SOLOS DOS TABULEIROS COSTEIROS, Aracaju, 2001. Anais. Aracaju, Embrapa Tabuleiros Costeiros, 2001. p.19-45.

LIBARDI, P. L. Dinâmica da água nos solos de tabuleiro. In: 500 ANOS DE USO DO SOLO NO BRASIL. Anais. Ilhéus, Editus, 2002. p.581-596.

LIMA, H.V.; SILVA, A.P.; JACOMINE, P.T.K.; ROMERO, R.E. \& LIBARDI, P.L. Identificação e caracterização de solos coesos no Estrado do Ceará. R. Bras. Ci. Solo, 28:467-476, 2004 .

MIRANDA, F.R. \& GOMES, A.R.M. Manejo da irrigação de coqueiro-anão. Fortaleza, Embrapa Agroindústria Tropical, 2006. 8p. (Circular Técnica, 25, on line)

NOGUEIRA, L.C.; NOGUEIRA, L.R.Q. \& MIRANDA, F.R. Irrigação do coqueiro. In: FERREIRA, J.M.S.; WARWICK, D.R.N. \& SIQUEIRA, L.A., eds. A Cultura do coqueiro no Brasil. 2.ed. Brasília, SPI, 1998. p.159-187.

OLIVIN, J. \& OCHS, R. Propriétés hydriques des sols et alimentation en eau des oléagineux pérennes en Afrique de l'Ouest. Oléagineux, 33:1-12, 1978.

PASSOS, E.E.M.; PASSOS, C.D. \& PRADO, C.H.B. Comportamento sazonal do potencial hídrico e das trocas gasosas de quatro variedades de coqueiro-anão. Aracaju, Embrapa Tabuleiros Costeiros, 2006. 19p. (Boletim de Pesquisa e Desenvolvimento, 18) 
REZENDE, J.O. Reflexões sobre as limitações agrícolas e o manejo dos solos coesos dos Tabuleiros Costeiros. In: 500 ANOS DE USO DO SOLO NO BRASIL, 2002, Ilhéus. Anais. Ilhéus, Editus, 2002. p.463-520.

RIBEIRO, L.P. Evolução da cobertura pedológica dos Tabuleiros Costeiros e a Gênese dos Horizontes Coesos. In: WORKSHOP COESÃO EM SOLOS DOS TABULEIROS COSTEIROS, Aracaju, 2001. Anais. Aracaju, Embrapa Tabuleiros Costeiros, 2001. p.61-88.

SANTANA, B.M.; SOUZA, L.S.; SOUZA, L.D. \& FONTES, L.E.F. Atributos físicos do solo e distribuição do sistema radicular de citros como indicadores de horizontes coesos em dois solos de Tabuleiros Costeiros do Estado da Bahia. R. Bras. Ci. Solo, 30:1-12, 2006.
SOUZA, L.D. \& SOUZA, L.S. Irrigação nos Tabuleiros Costeiros no Nordeste do Brasil. Portal do Agronegócio. Disponível em: $<$ http://www.portaldoagronegocio.com.br $>$ Acesso em: 06 out. 2008.

SOUZA, L.S.; BORGES, A.L.; CINTRA, F.L.D.; SOUZA, L.D. \& IVO, W.M.P.M. Perspectivas de uso dos solos dos Tabuleiros Costeiros. In: 500 ANOS DE USO DO SOLO NO BRASIL, Ilhéus, 2002. Anais. Ilhéus, Editus, 2002. p.521-579.

van GENUCHTEN, M.T. A closed-form equation for predicting the hydraulic conductivity of unsaturated soils. Soil Sci. Soc. Am. J., 44:892-897, 1980. 
